\title{
Microstructural Instability of an Experimental Nickel-Based Single-Crystal Superalloy
}

\author{
Bin Yin ${ }^{1,2} \cdot$ Guang Xie ${ }^{1} \cdot$ Xiangwei Jiang ${ }^{1} \cdot$ Shaohua Zhang ${ }^{1} \cdot$ Wei Zheng ${ }^{1} \cdot$ Langhong Lou $^{1}$
}

Received: 29 November 2019 / Revised: 6 January 2020 / Published online: 12 May 2020

(c) The Chinese Society for Metals (CSM) and Springer-Verlag GmbH Germany, part of Springer Nature 2020

\begin{abstract}
Microstructural instability with the precipitation of topologically close-packed (TCP) phases of an experimental nickel-based single-crystal superalloy has been investigated. A significant amount of $\sigma$ phases are distinguished in the interdendritic region of the as-cast samples after thermal exposure at $900{ }^{\circ} \mathrm{C}$ for $1000 \mathrm{~h}$. The $\sigma$ phases are preferentially precipitated at the periphery of coarse $\gamma / \gamma^{\prime}$ eutectic, and their morphological evolution from needles to granules is observed. Microstructural analysis suggests that the local segregation of $\mathrm{Cr}$ and $\mathrm{Ti}$ at the periphery of coarse $\gamma / \gamma^{\prime}$ eutectic accounts for the formation of $\sigma$ phases in the as-cast samples. After heat treatment with low solution temperature and short holding time, the dendritic segregation of alloying elements (i.e., W, Re, Ti and Ta) and the volume fraction of $\gamma^{\prime}$ phase in the interdendritic region are similar to that of the as-cast samples. However, no TCP phases are present in the interdendritic region of the heat-treated samples after thermal exposure, which is primarily ascribed to the elimination of local segregation of $\mathrm{Cr}$ and $\mathrm{Ti}$ near the coarse $\gamma / \gamma^{\prime}$ eutectic. Moreover, small quantities of $\mu$ phases are precipitated in the secondary dendrite arm near the interdendritic region after thermal exposure, due to the increased volume fraction of $\gamma^{\prime}$ phase and the concomitant enrichment of $\mathrm{W}$ and Re in the $\gamma$ matrix.
\end{abstract}

Keywords Nickel-based single-crystal superalloy $\cdot$ Topologically close-packed (TCP) phases $\cdot$ Segregation $\cdot$ Eutectic

\section{Introduction}

Ni-based single-crystal (SX) superalloys are widely applied in industrial gas turbines, aircrafts and jet engines due to their excellent mechanical properties at elevated temperature. In order to improve high-temperature strength and creep resistance, high levels of refractory elements, such as Mo, W and Re, are added in SX superalloys, which strongly promote the precipitation of topologically close-packed (TCP) phases [1-3]. TCP phases, such as $\sigma$ and $\mu$ phases, are detrimental to the mechanical properties of SX superalloys since they promote the depletion of refractory elements

Available online at http://link.springer.com/journal/40195.

Guang Xie

gxie@imr.ac.cn

1 Superalloys Division, Institute of Metal Research, Chinese Academy of Sciences, Shenyang 110016, China

2 School of Materials Science and Engineering, University of Science and Technology of China, Hefei 230026, China in the $\gamma$ matrix, and can initiate cracks or accelerate crack propagation [4-6].

Usually, TCP phases are preferentially distributed in the dendrite core due to the dendritic segregation of Re and $\mathrm{W}$ [7]. In order to avoid the formation of TCP phases, heat treatment with high solution temperature and long holding time was applied to reduce the dendritic segregation [8-10]. For example, the volume fraction of TCP phases in the CMSX-4 superalloy significantly decreased after thermal exposure by elevating temperature and prolonging holding time of the solution heat treatment to reduce the dendritic segregation of $\mathrm{Re}$ and $\mathrm{W}$ [8]. However, it seems that the TCP phases do not change monotonically with the variation of dendritic segregation [11-14]. In our previous study [11], the volume fraction of TCP phases in a heat-treated SX superalloy increased after thermal exposure by elevating solution temperature, although the dendritic segregations of $\mathrm{W}$ and Re were reduced. It has been reported that TCP phases were distinguished in the interdendritic region of an as-cast SX superalloy after thermal exposure, which was ascribed to the partitioning of Ta, leading to an increase in the volume fraction of $\gamma^{\prime}$ phase in the interdendritic region and a concomitant enrichment of Mo and 
particularly Crin the $\gamma$ matrix [12]. Long [14] has also found $\sigma$ phases formed at the periphery of the eutectic in the interdendritic region even during solidification process in a polycrystalline superalloy. They suggested the local segregation of $\mathrm{Cr}$, $\mathrm{Mo}, \mathrm{Co}$ and $\mathrm{W}$ at the periphery of the eutectic accounts for the formation of $\sigma$ phases. However, more evidences are required to clarify this mechanism. Therefore, it is suggested that the precipitation of TCP phases is not only determined by the dendritic segregation of refractory elements, such as W and Re.

In this study, a significant amount of TCP phases precipitated in the interdendritic region of an as-cast SX superalloy after thermal exposure at $900{ }^{\circ} \mathrm{C}$. However, no TCP phases were distinguished in the interdendritic region of heat-treated (with low solution temperature and short holding time) samples after thermal exposure, although the strong dendritic segregation of $\mathrm{W}, \mathrm{Re}, \mathrm{Ti}$ and Ta could be found. This work aims to further investigate the relationship between the dendritic segregation and the precipitation of TCP phases. Moreover, important guidance for further reducing TCP phases in as-cast SX superalloys, especially for the superalloys which serviced in the as-cast condition, such as DD26 SX superalloy, could be summarized from the present study.

\section{Experimental}

The nominal chemical compositions of the experimental superalloy are listed in Table 1 . Single-crystal bars were cast by directional solidification in a Bridgman furnace, and the crystallographic orientation of select samples was close to the $<001>$ direction (deviation less than $10^{\circ}$ ). The samples were cut into slices with the size of $16 \mathrm{~mm}$ in diameter and $5 \mathrm{~mm}$ in thickness by electrical discharge machining. Some samples were subjected to heat treatment with low solution temperature and short holding time, as listed in Table 2. Both as-cast and heat-treated samples were thermally exposed at $900{ }^{\circ} \mathrm{C}$ for $1000 \mathrm{~h}$.

Standard metallographic techniques were employed for the preparation of samples. To reveal the $\gamma-\gamma^{\prime}$ microstructure, the samples were etched with a solution of $4 \mathrm{~g} \mathrm{CuSO}_{4}, 10 \mathrm{~mL}$ $\mathrm{HCl}$, and $20 \mathrm{~mL} \mathrm{H}_{2} \mathrm{O}$. Another etchant consisting of $80 \mathrm{~mL}$ $\mathrm{HCl}, 20 \mathrm{~mL} \mathrm{H}_{2} \mathrm{O}, 2 \mathrm{~mL} \mathrm{HNO}_{3}$ and $16 \mathrm{~g} \mathrm{FeCl}_{3}$ was used to investigate the TCP phases. Microstructural observations were carried out using a field-emission Inspect F50 scanning electron microscope (SEM) operating at $20 \mathrm{kV}$. The volume fraction of $\gamma^{\prime}$ phases was determined using the SEM micrographs.

Compositional information and elemental mapping were obtained using a Cameca SX100 electron probe microanalyzer (EPMA, Shimadzu EPMA1610) operating at $20 \mathrm{kV}$.
The detailed methods of quantitatively measuring the compositions of dendrite core and interdendritic region have been reported elsewhere [11]. The degree of dendritic segregation was characterized using the segregation ratio $K_{i}$, which was defined as Eq. (1) [15]. By definition, $K_{i}$ is taken to be the ratio of the dendrite core composition over the interdendritic composition level. The value of $K_{i}$ greater or less than unity means that the element $i$ segregates to the dendrite or the interdendritic region.

$K_{i}=C_{\text {dendrite }}^{i} / C_{\text {interdendrite }}^{i}$

About $500 \mu \mathrm{m}$ disks in thickness were cut from the samples perpendicular to the [001] direction for transmission electron microscopy (TEM) analysis. They were mechanically ground to $50 \mu \mathrm{m}$ in thickness, and $3 \mathrm{~mm}$ disks in diameter were punched out from the pieces. Finally, they were electrochemically polished at $-25^{\circ} \mathrm{C}$ and $20 \mathrm{~V}$ in a solution of $10 \%$ perchloric acid in alcohol. An FEI Tecnai F20 transmission electron microscopy (TEM) was used to analyze the microstructure and composition of TCP phases.

\section{Results}

Scanning electron micrographs of the as-cast sample are presented in Fig. 1. Typical dendritic pattern with a few of $\gamma / \gamma^{\prime}$ eutectics in the interdendritic region is shown in Fig. 1a. The fine $\gamma^{\prime}$ phases in the dendrite core (Fig. 1b) and coarse $\gamma^{\prime}$ phases in the interdendritic region (Fig. 1c) were found. The $\gamma / \gamma^{\prime}$ eutectic can be morphologically characterized by fine $\gamma / \gamma^{\prime}$ network and coarse $\gamma^{\prime}$ phase as marked in Fig. 1d. Unlike the coarse $\gamma^{\prime}$ phase in the interdendritic region, a layer of fine $\gamma^{\prime}$ phase was observed at the periphery of coarse $\gamma / \gamma^{\prime}$ eutectic. After solution heat treatment, the fine $\gamma^{\prime}$ phases were dissolved, and the $\gamma$ zone formed at the periphery of coarse $\gamma / \gamma^{\prime}$ eutectic, while the coarse $\gamma^{\prime}$ phases were not dissolved (Fig. 2a). Some fine precipitates were observed in the $\gamma$ zone as marked by arrow in Fig. 2b. The microstructures of the heat-treated (with solution and aging heat treatment) samples are shown in Fig. 3. The regular and cuboidal $\gamma^{\prime}$ phases

Table 2 Heat treatment schedule for the experimental alloy

\begin{tabular}{ll}
\hline Experiment & Heat treatment schedule \\
\hline Solution heat treatment & $600{ }^{\circ} \mathrm{C}-1 \mathrm{~h}-1000^{\circ} \mathrm{C}-1 \mathrm{~h}-1260^{\circ} \mathrm{C} / \mathrm{AC}$ \\
Aging heat treatment & $1130{ }^{\circ} \mathrm{C} / 4 \mathrm{~h} / \mathrm{AC}+870^{\circ} \mathrm{C} / 24 \mathrm{~h} / \mathrm{AC}$ \\
\hline
\end{tabular}

Table 1 Nominal compositions of the experimental alloy (wt\%)

\begin{tabular}{llllllllll}
\hline $\mathrm{Cr}$ & $\mathrm{Co}$ & $\mathrm{Al}$ & $\mathrm{Ti}$ & $\mathrm{W}$ & $\mathrm{Mo}$ & $\mathrm{Ta}$ & $\mathrm{Re}$ & $\mathrm{C}$ & $\mathrm{Ni}$ \\
\hline 9 & 9 & 3.8 & 3.8 & 4.5 & 1 & 5.5 & 2 & 0.05 & Bal. \\
\hline
\end{tabular}



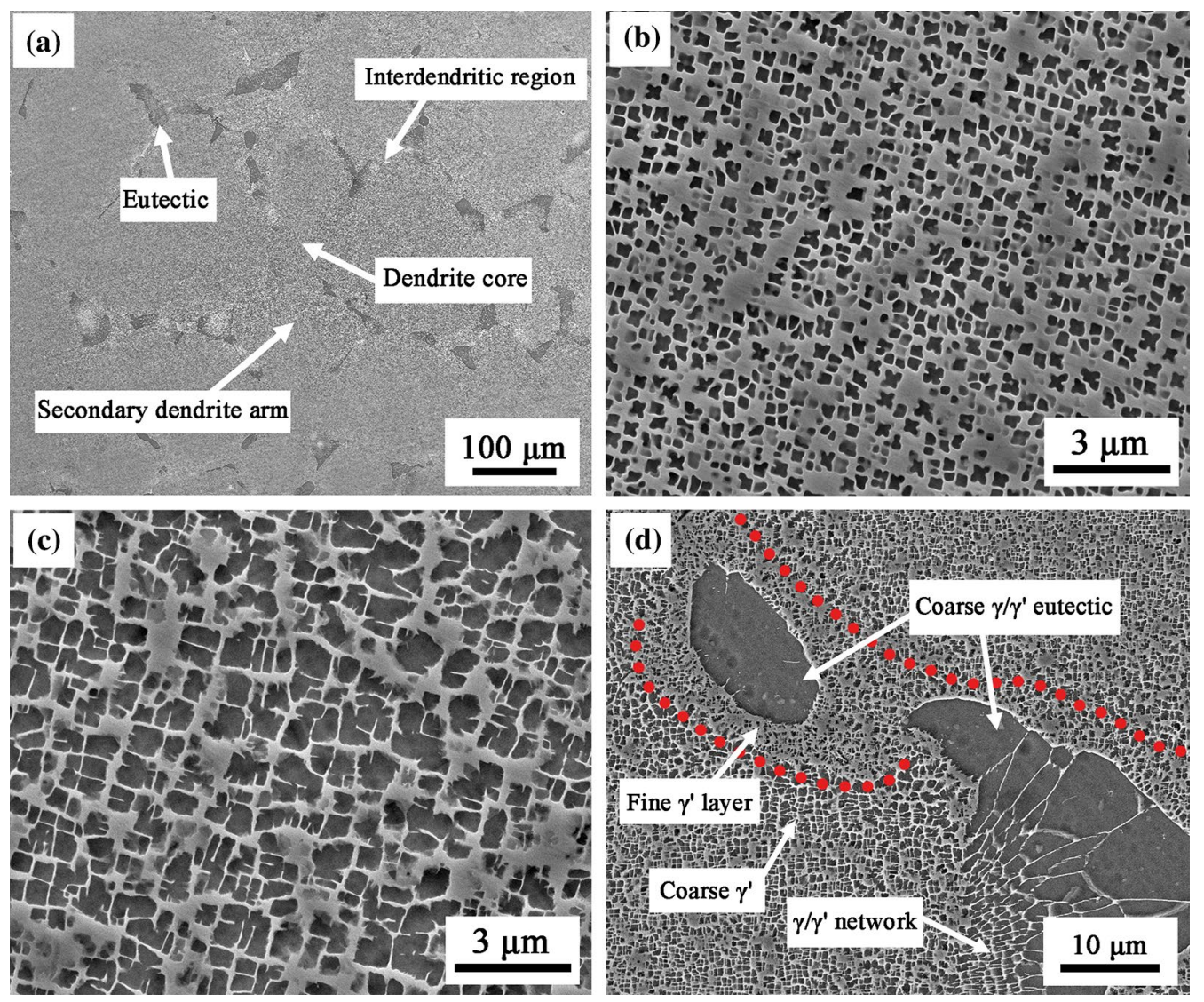

Fig. 1 Scanning electron micrographs of $\mathbf{a}$ as-cast sample in $\mathbf{b}$ dendrite core, $\mathbf{c}$ and $\mathbf{d}$ interdendritic region

could be observed in the dendrite core (Fig. 3a). As compared with the coarse $\gamma^{\prime}$ phases in the interdendritic region (Fig. 3b), the $\gamma^{\prime}$ phases were obviously fine at the periphery of coarse $\gamma / \gamma^{\prime}$ eutectic (Fig. 3c). It is notable that the volume fraction of the fine $\gamma^{\prime}$ phases is much lower than that of the coarse $\gamma^{\prime}$ phases. In addition, the volume fractions of $\gamma^{\prime}$ phases in the interdendritic region of as-cast and heat-treated samples were $55.6 \pm 1.1 \%$ and $54.6 \pm 0.5 \%$, respectively.

The segregation ratios are shown in Fig. 4. It was found that $\mathrm{W}, \mathrm{Mo}, \mathrm{Cr}$, Co and Re segregated to the dendrite core, while $\mathrm{Al}, \mathrm{Ti}$ and $\mathrm{Ta}$ partitioned to the interdendritic region in the as-cast sample. Moreover, it was obvious that
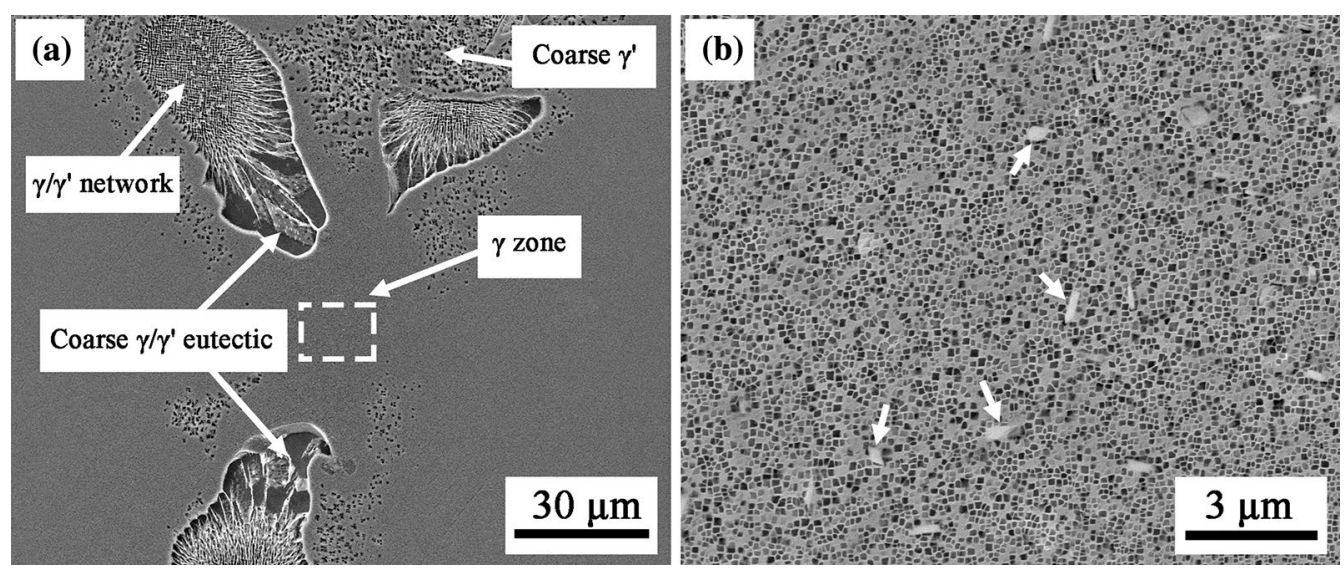

Fig. 2 Scanning electron micrographs of the sample after solution heat treatment $\mathbf{a}, \mathbf{b}$ is magnified morphology of the white zone in $\mathbf{a}$ 

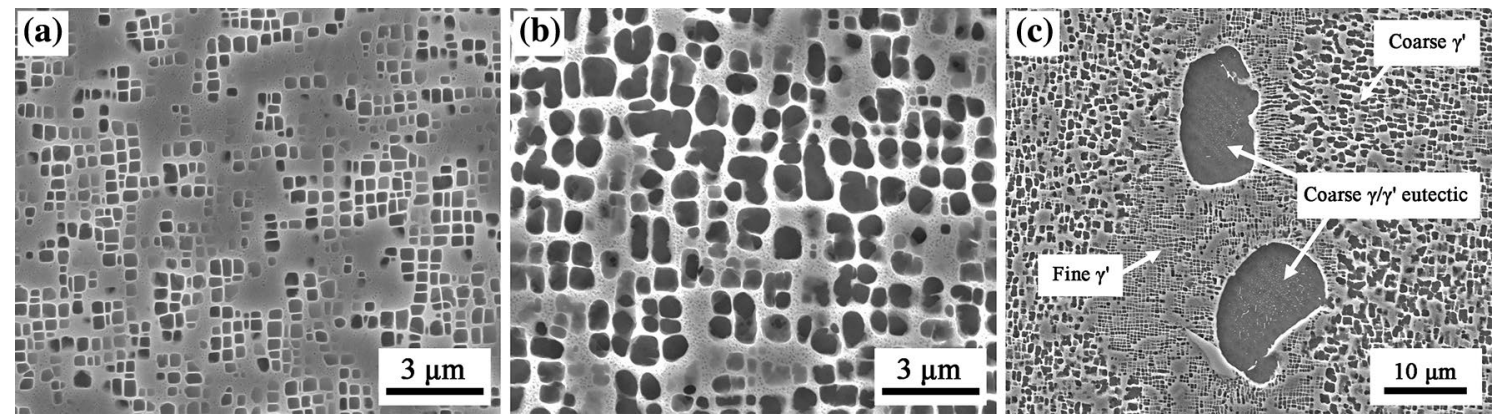

Fig. 3 Scanning electron micrographs of the heat-treated sample: a dendrite core, $\mathbf{b}, \mathbf{c}$ interdendritic region

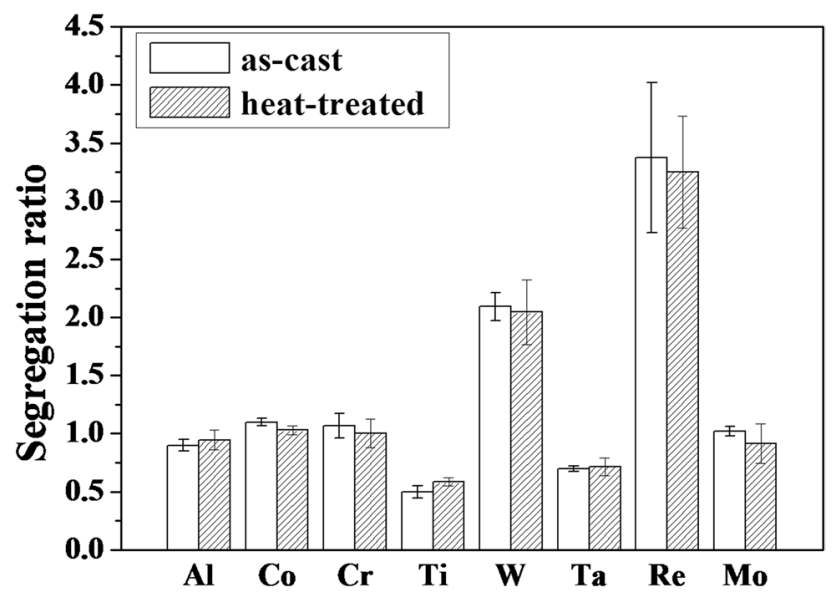

Fig. 4 Segregation ratio of as-cast and heat-treated samples

the dendritic segregation of $\mathrm{W}, \mathrm{Re}, \mathrm{Ti}$ and Ta was notably strong. Compared with the as-cast sample, the dendritic segregation was only slightly reduced in the heat-treated sample. It was indicated that the heat treatment with low solution temperature and short holding time was far from eliminating dendritic segregation. EPMA element maps of $\gamma / \gamma^{\prime}$ eutectic of the as-cast and heat-treated samples are shown in Figs. 5 and 6 , respectively. It was clearly observed that the coarse $\gamma / \gamma^{\prime}$ eutectic was enriched in Al, Ti and Ta. Moreover, the local segregation of $\mathrm{Cr}$ and $\mathrm{Ti}$ was visible at the periphery of coarse $\gamma / \gamma^{\prime}$ eutectic in the as-cast sample (Fig. 5). However, the local segregation of $\mathrm{Cr}$ and $\mathrm{Ti}$ was eliminated in the heattreated sample (Fig. 6).

The microstructures of the as-cast sample subjected to thermal exposure at $900{ }^{\circ} \mathrm{C}$ are shown in Fig. 7. After exposure at $900{ }^{\circ} \mathrm{C}$ for $100 \mathrm{~h}$, a small amount of granular and needle-like TCP phases could be clearly distinguished at the periphery of coarse $\gamma / \gamma^{\prime}$ eutectic (Fig. 7a). Subsequent annealing resulted in mass precipitation of TCP phases surrounding the coarse $\gamma / \gamma^{\prime}$ eutectic, extending throughout the interdendritic region (Fig. 7c). Moreover, the morphological evolution of TCP phases from needles to granules can be seen, as shown in Fig. 8. After exposure at $900{ }^{\circ} \mathrm{C}$ for
$1000 \mathrm{~h}$, the granular TCP phases were distributed around the eutectic with the needle-like TCP phases away from the eutectic. These TCP phases were identified as $\sigma$ phase by selective area electron diffraction (SAED) (Fig. 9a, c). The compositions of $\sigma$ phases were determined by TEM with energy-dispersive X-ray spectroscopy (EDS), as listed in Table 3. They were enriched in $\mathrm{Re}$ and Cr. However, in the heat-treated samples, no TCP phases could be observed in the dendrite core and interdendritic region up to $1000 \mathrm{~h}$ exposure at $900{ }^{\circ} \mathrm{C}$ (Fig. 10a, b). Only a small amount of TCP phases were detected in the secondary dendrite arm near the interdendritic region (Fig. 10c), which were identified as $\mu$ phase (Fig. 9b, d). They were enriched in Re and $\mathrm{W}$, as listed in Table 3 .

\section{Discussion}

As the main forming elements of TCP phases, $\mathrm{W}$ and Re significantly increase the propensity to TCP phase formation $[16,17]$. The dendritic segregation of $\mathrm{W}$ and $\mathrm{Re}$ is prone to form, which strongly accelerates the precipitation of TCP phases $[7,10]$. In the present paper, it is noted that the dendritic segregation of $\mathrm{W}, \mathrm{Re}, \mathrm{Ti}$ and Ta is particularly strong in both the as-cast and heat-treated samples. However, the behavior of TCP precipitations is quite different in the two samples (Figs. 7, 10).

In the as-cast sample, a significant amount of $\sigma$ phases are observed in the interdendritic region (Fig. 7). Karunaratne et al. [12] attributed it to the increased volume fraction of $\gamma^{\prime}$ phase in the interdendritic region and a corresponding enrichment of Mo and $\mathrm{Cr}$ in the $\gamma$ matrix. However, in the present study, $\sigma$ phases are preferentially precipitated at the periphery of coarse $\gamma / \gamma^{\prime}$ eutectic, where the volume fraction of $\gamma^{\prime}$ phase is quite low (Figs. 1d, 7a).

It has been reported that the coarse $\gamma / \gamma^{\prime}$ eutectics with high content of Ta and Ti form at the last stage of solidification, and the excess $\mathrm{Ti}$ is enriched at the front of the coarse $\gamma / \gamma^{\prime}$ eutectic $[18,19]$. Moreover, the formation of coarse $\gamma / \gamma^{\prime}$ eutectic would cause the accumulation of $\mathrm{Cr}$ 

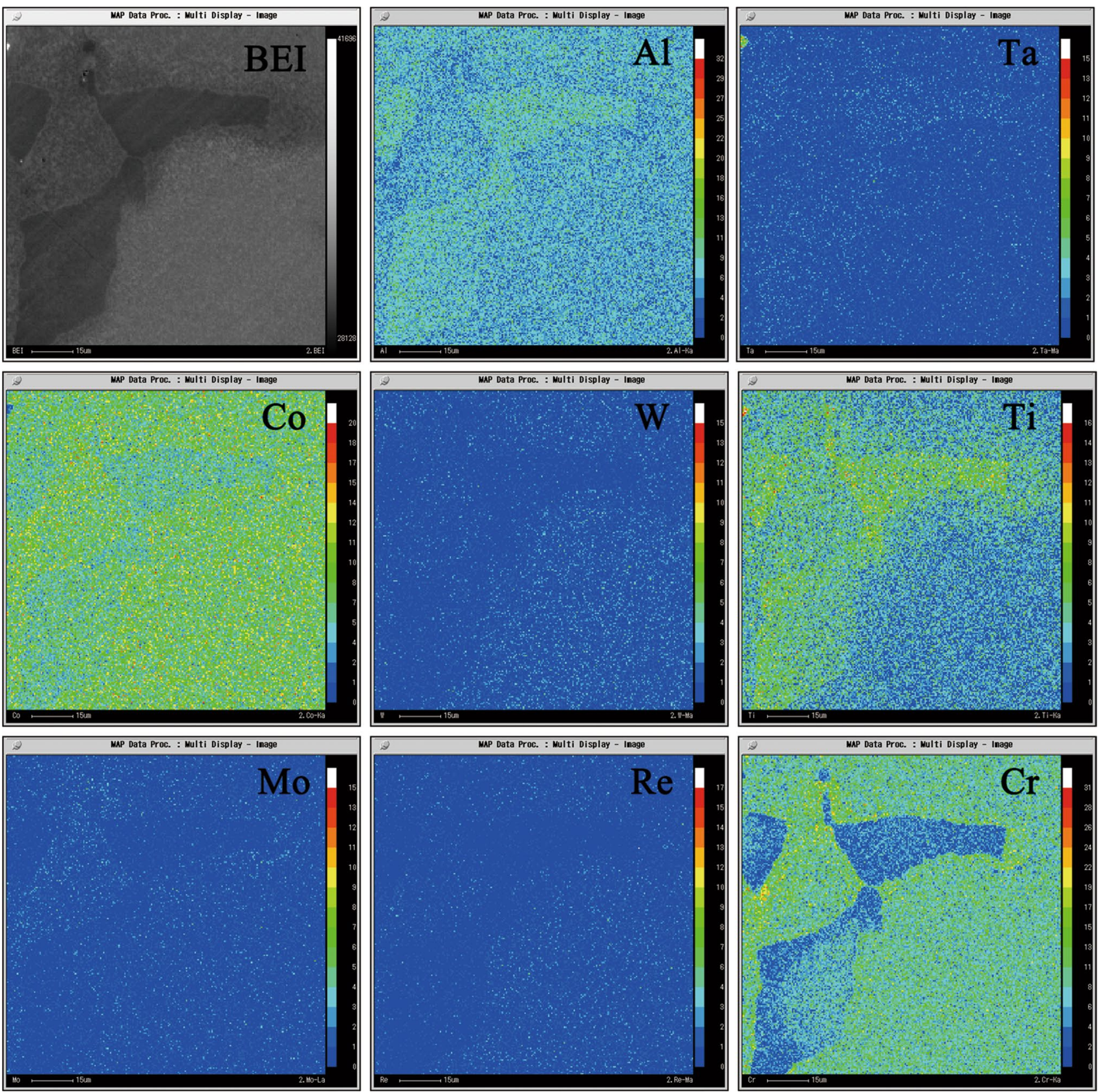

Fig. 5 EPMA element maps of $\gamma / \gamma^{\prime}$ eutectic in the as-cast sample

and Mo ahead of the eutectic due to the low solubility of these elements in the $\gamma^{\prime}$ phase [20-22]. The local segregation of $\mathrm{Ti}$ and $\mathrm{Cr}$ is visible near the coarse $\gamma / \gamma^{\prime}$ eutectic, as shown in Fig. 5. Ti is shown to cause a stronger partitioning of $\gamma$ matrix forming elements, such as $\mathrm{Re}, \mathrm{W}, \mathrm{Cr}$, Co and Mo, to the $\gamma$ phase, which in turn promotes the precipitation of TCP phases [23, 24]. Moreover, as the main forming element of $\sigma$ phases, Cr obviously increases the susceptibility of $\sigma$ phases formation [25]. Therefore, $\sigma$ phases in the form of granules and needles are preferentially precipitated at the periphery of coarse $\gamma / \gamma^{\prime}$ eutectic after thermal exposure at $900{ }^{\circ} \mathrm{C}$ for $100 \mathrm{~h}$ (Fig. 7a). It is similar to the formation of $\sigma$ phase at the eutectic in a polycrystalline $\mathrm{Ni}$-based superalloy and $\alpha$-Cr precipitation in the $\beta$ phase observed in a $\mathrm{Ni}_{3} \mathrm{Al}$-based superalloy in the final stages of the solidification process, due to elemental segregation, especially $\mathrm{Cr}$, in the residual liquid $[14,26]$. It has previously been shown that the $\sigma$ needles arranging very regularly have fully coherent interfaces with the surrounding matrix [27-29]. The morphological evolution of 

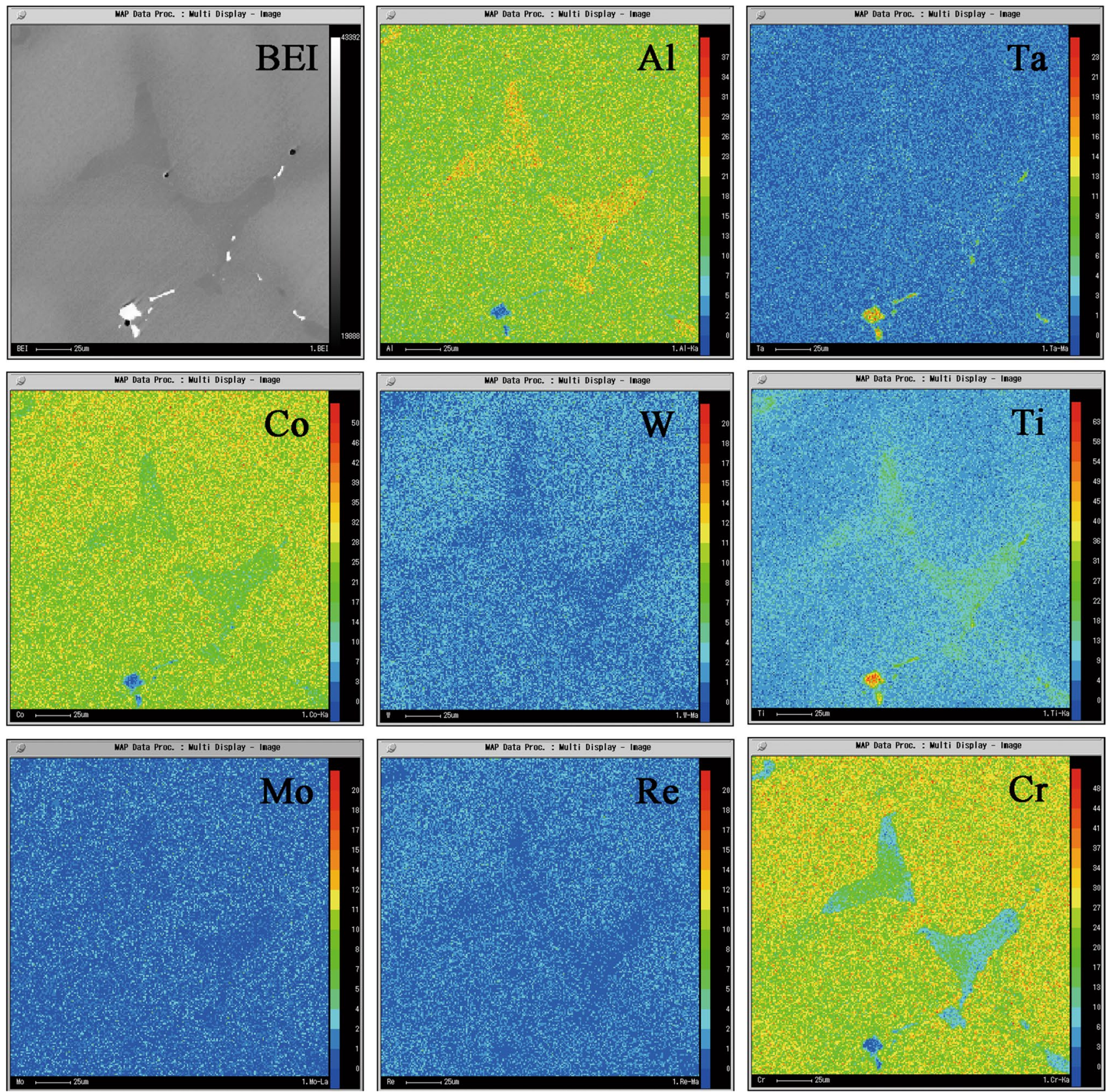

Fig. 6 EPMA element maps of $\gamma / \gamma^{\prime}$ eutectic in the heat-treated sample
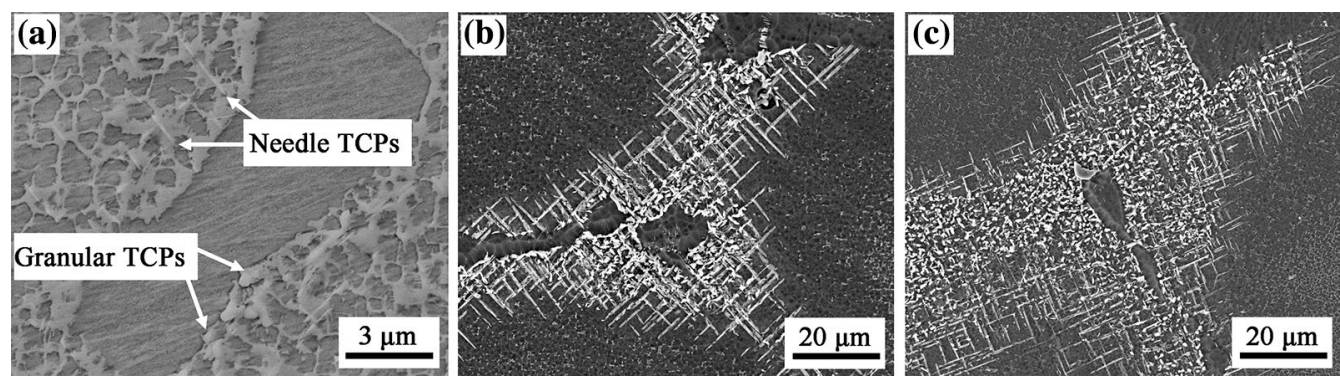

Fig. 7 Microstructures in the interdendritic region of the as-cast sample after thermal exposure at $900{ }^{\circ} \mathrm{C}$ for a $100 \mathrm{~h}, \mathbf{b} 240 \mathrm{~h}, \mathbf{c} 1000 \mathrm{~h}$ 

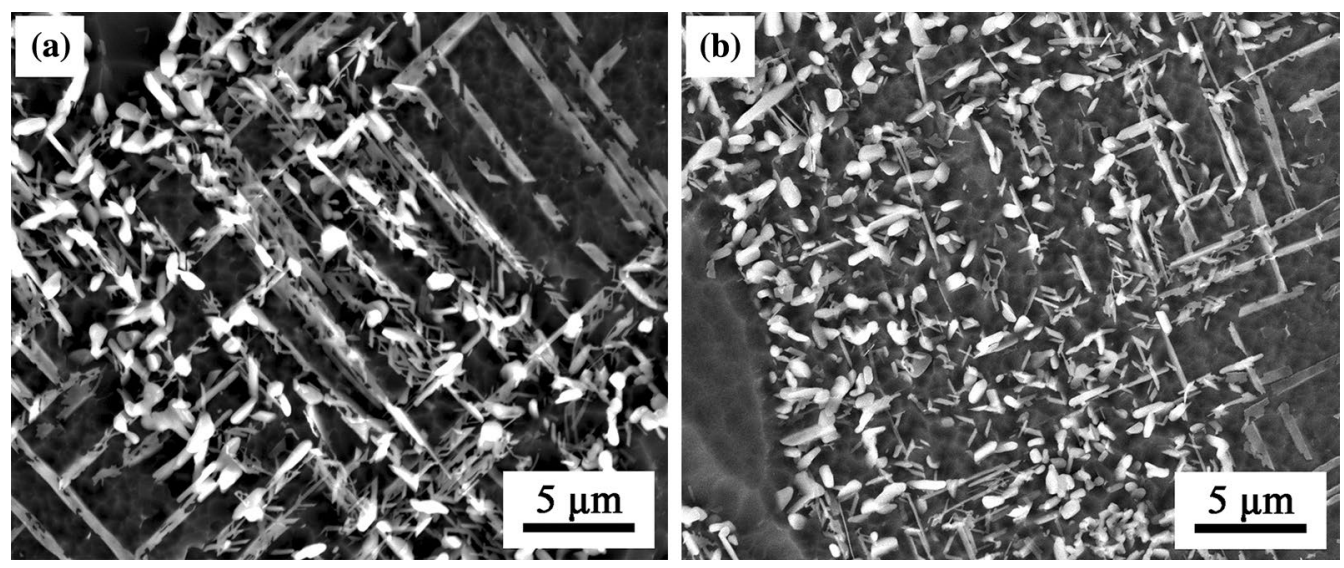

Fig. 8 Morphological evolution of TCPs near the eutectic after thermal exposure at $900{ }^{\circ} \mathrm{C}$ for a $240 \mathrm{~h}, \mathbf{b} 1000 \mathrm{~h}$
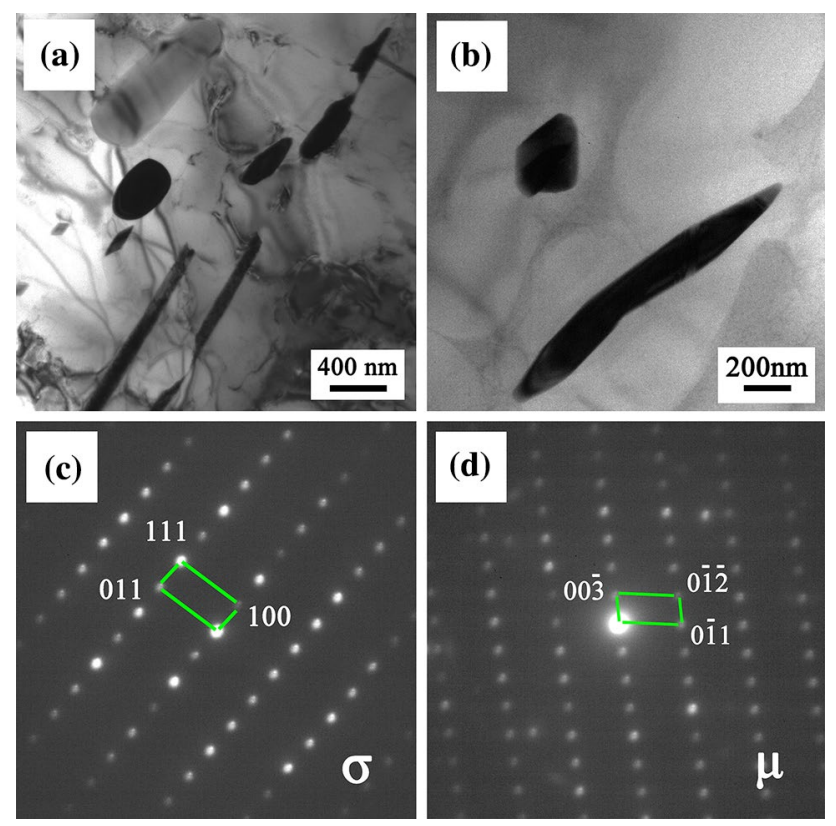

Fig. 9 TEM micrograph and diffraction pattern associated with a, $\mathbf{c} \sigma$ phase in the as-cast sample and $\mathbf{b}, \mathbf{d} \mu$ phase in the heat-treated sample

$\sigma$ phases from needle-like to granular leads to a reduction in the coherency of the $\sigma$-matrix interface. Moreover, the granular precipitates transformed to spheroidization would minimize the interfacial energy [29]. It is possible that the interdiffusion between the coarse $\gamma / \gamma^{\prime}$ eutectic and the interdendritic region significantly promotes this morphological evolution after further thermal exposure. Therefore, the morphological evolution from needle-like to granular is observed especially at the periphery of eutectics (Fig. 8). In addition, no TCP phases are present in the dendrite core after thermal exposure, owing to the high volume fraction of $\gamma$ matrix and low supersaturation of $\mathrm{Re}$ and $\mathrm{W}$ in $\gamma$ matrix, as reported in the previous study [11].

In the heat-treated sample, no TCP phases are distinguished in the interdendritic region after thermal exposure at $900{ }^{\circ} \mathrm{C}$ for $1000 \mathrm{~h}$ (Fig. 10). The dendritic segregation of $\mathrm{W}, \mathrm{Re}, \mathrm{Ti}$ and Ta has changed slightly, due to the low solution temperature and short holding time (Fig. 4). In addition, the volume fraction of $\gamma^{\prime}$ phase in the interdendritic region of heat-treated sample is similar to that of the as-cast sample. In that case, the quite different behavior of TCP precipitation in the two types of samples cannot be rationalized well. It is suggested that the eliminating segregation of $\mathrm{Ti}$ and $\mathrm{Cr}$ at the periphery of coarse $\gamma / \gamma^{\prime}$ eutectic primarily accounts for the quite different behavior of TCP precipitation of the heat-treated sample in comparison with that of the as-cast sample.

The fine $\gamma^{\prime}$ phases were dissolved, and the $\gamma$ zone formed at the periphery of coarse $\gamma / \gamma^{\prime}$ eutectic after lowtemperature solution heat treatment. It is noted that the $\gamma$ zone is prone to TCP phase formation due to the segregation of $\mathrm{Ti}$ and $\mathrm{Cr}$. The fine precipitates in the $\gamma$ zone are

Table 3 Compositions (wt $\%$ ) of $\sigma$ in the interdendritic region of the as-cast sample and $\mu$ in the secondary dendrite arm of the heat-treated sample determined by TEM with EDS

\begin{tabular}{llllllllll}
\hline Phase & Cr & Co & W & Mo & Al & Ti & Ta & Re & Ni \\
\hline$\sigma$ & 25.5 & 11.2 & 11.5 & 6.4 & 1.1 & 2.1 & 2.6 & 13.1 & 26.6 \\
$\mu$ & 11.9 & 9.4 & 21.8 & 3.8 & 1.3 & 1.5 & 2.9 & 17.7 & 30.3 \\
\hline
\end{tabular}



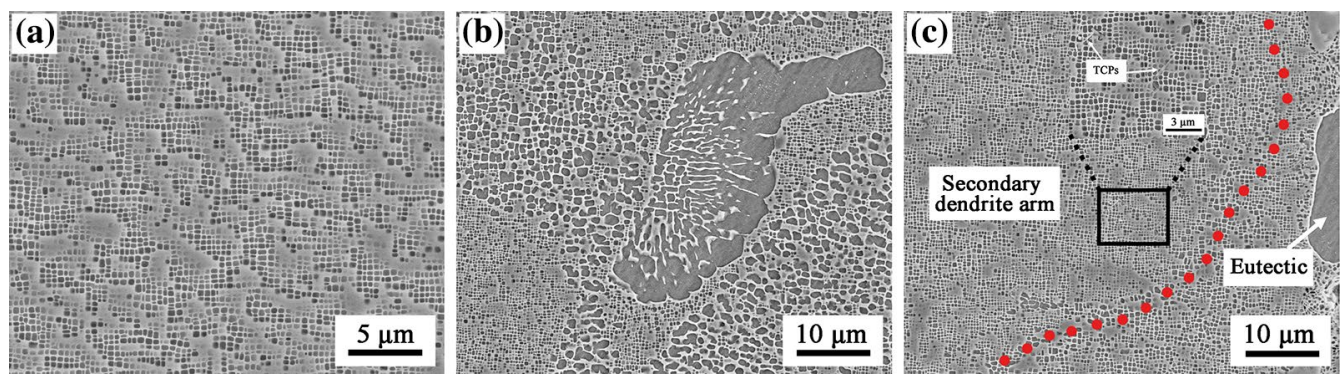

Fig. 10 Microstructures of the heat-treated sample after thermal exposure at $900{ }^{\circ} \mathrm{C}$ for $1000 \mathrm{~h}$ in $\mathbf{a}$ dendrite core, $\mathbf{b}$ interdendritic region, $\mathbf{c}$ secondary dendrite arm

considered to be $\sigma$ phases, which are precipitated during the air cooling of solution heat treatment (Fig. 2b). These $\sigma$ phases are absolutely dissolved in the subsequent aging heat treatment.

After solution and aging heat treatment, the segregation of $\mathrm{Ti}$ and $\mathrm{Cr}$ at the periphery of coarse $\gamma / \gamma^{\prime}$ eutectic is eliminated (Fig. 6). Therefore, there is no preferential nucleation position of TCP phases in the interdendritic region. However, $\mathrm{Al}, \mathrm{Ti}$ and $\mathrm{Ta}$ diffuse from the interdendritic region to the dendrite core, leading to increased volume fraction of $\gamma^{\prime}$ phase in the secondary dendrite arm and resulting high enrichment of $\mathrm{W}$ and $\mathrm{Re}$ in $\gamma$ matrix. The diffusion distance of $\mathrm{Al}, \mathrm{Ti}$ and $\mathrm{Ta}$ is limited, due to the low temperature and short holding time of heat treatment. Therefore, small quantities of W, Re-rich $\mu$ phases are precipitated in the secondary dendrite arm near the interdendritic region rather than in the dendrite core.

\section{Conclusions}

Microstructural instability of the as-cast and heat-treated (with low solution temperature and short holding time) SX superalloys associated with the precipitation of topologically close-packed (TCP) phases was investigated. The following conclusions can be drawn:

1. Strong dendritic segregation of $\mathrm{W}, \mathrm{Re}, \mathrm{Ti}$ and $\mathrm{Ta}$ was found both in the as-cast and heat-treated samples. However, local segregation of $\mathrm{Ti}$ and $\mathrm{Cr}$ was present at the periphery of coarse $\gamma / \gamma^{\prime}$ eutectic in the as-cast samples, and their local segregations were eliminated in the heattreated samples.

2. A significant amount of $\sigma$ phases were distinguished in the interdendritic region of the as-cast sample after thermal exposure at $900{ }^{\circ} \mathrm{C}$ for $1000 \mathrm{~h}$. The $\sigma$ phases were preferentially precipitated at the periphery of coarse $\gamma / \gamma^{\prime}$ eutectic, and the morphological evolution of $\sigma$ phases from needles to granules was observed. No TCP phases were present in the interdendritic region, and small quantities of $\mu$ phases were detected in the secondary dendrite arm of the heat-treated samples after thermal exposure at $900{ }^{\circ} \mathrm{C}$ for $1000 \mathrm{~h}$.

3. It is believed that the local segregation of $\mathrm{Ti}$ and $\mathrm{Cr}$ at the periphery of coarse $\gamma / \gamma^{\prime}$ eutectic accounts for the mass $\sigma$ phases precipitation in the interdendritic region of the as-cast samples. The increased volume fraction of $\gamma^{\prime}$ phase in the secondary dendrite arm leads to high enrichment of $\mathrm{W}$ and Re in the $\gamma$ matrix, then $\mu$ phases precipitate in the heat-treated samples.

Acknowledgements This work was financially supported by the National Natural Science Foundation of China (Nos. 51771204, U1732131, 51911530154, 91860201 and 51631008) and the National Science and Technology Major Project (No. 2017-VII-0008-0101).

\section{References}

[1] G.L. Erickson, in Superalloys, ed. by D.J. Deye, D.L. Anton, A.D. Cetel, M.V. Nathal, T.M. Pollock, D.A. Woodford (TMS, Champion, 1996), p. 35

[2] W.S. Walston, in Superalloys, ed. by D.J. Deye, D.L. Anton, A.D. Cetel, M.V. Nathal, T.M. Pollock, D.A. Woodford (TMS, Champion, 1996), p. 27

[3] S. Walston, in Superalloys, ed. by K.A. Green, T.M. Pollock, H. Harada, T.E. Howson, R.C. Reed, J.J. Schirra, S. Walston (TMS, Philadelphia, 2004), p. 15

[4] M. Simonetti, P. Caron, Mater. Sci. Eng. A 254, 1 (1998)

[5] A. Volek, R.F. Singer, R. Buergel, J. Grossmann, Y. Wang, Metall. Mater. Trans. A 37, 405 (2006)

[6] Z.K. Zhang, Z.F. Yue, J. Alloys Compd. 746, 84 (2018)

[7] A. Volek, in Superalloys, ed. by K.A. Green, T.M. Pollock, H. Harada, T.E. Howson, R.C. Reed, J.J. Schirra, S. Walston (TMS, Philadelphia, 2004), p. 713

[8] B.C. Wilson, J.A. Hickman, G.E. Fuchs, JOM 55, 35 (2003)

[9] K. Park, P. Withey, Adv. Eng. Mater. 20 (2018), Art. No. 1700987

[10] H.T. Pang, L.J. Zhang, R.A. Hobbs, H.J. Stone, C.M.F. Rae, Metall. Mater. Trans. A 43, 3264 (2012)

[11] B. Yin, G. Xie, L.H. Lou, J. Zhang, Scr. Mater. 173, 1 (2019)

[12] M.S.A. Karunaratne, C.M.F. Rae, R.C. Reed, Metall. Mater. Trans. A 32, 2409 (2001)

[13] A. Cheng, S.S. Li, X.B. Zhao, J. Zhou, Y.J. Guo, Z.P. Sun, X.D. Song, S.K. Gong, J. Alloys Compd. 722, 740 (2017) 
[14] F. Long, Y.S. Yoo, C.Y. Jo, S.M. Seo, H.W. Jeong, Y.S. Song, T. Jin, Z.Q. Hu, J. Alloys Compd. 478, 181 (2009)

[15] R.M. Kearsey, in Superalloys, ed. by K.A. Green, T.M. Pollock, H. Harada, T.E. Howson, R.C. Reed, J.J. Schirra, S. Walston (TMS, Philadelphia, 2004), p. 801

[16] P.L. Mao, Y. Xin, K. Han, W.G. Jiang, Acta Metall. Sin. Engl. Lett. 22, 365 (2009)

[17] K.Y. Cheng, Y.J. Chang, T. Jin, Z.Q. Hu, J. Alloys Compd. 536, 7 (2012)

[18] Y.J. Liang, J. Li, A. Li, X.T. Pang, H.M. Wang, Scr. Mater. 127, 58 (2017)

[19] S.M. Seo, J.H. Lee, Y.S. Yoo, C.Y. Jo, H. Miyahara, K. Ogi, Metall. Mater. Trans. A 42, 3150 (2011)

[20] Y.X. Zhu, S.N. Zhang, L.Y. Xu, J. Bi, Z.Q. Hu, C.X. Shi, in Superalloys, ed. by S.D. Antolovich, R.W. Stusrud, R.A. MacKay, D.L. Anton, T. Khan, R.D. Kissinger, D.L. Klarstrom (TMS, Warrendale, 1988), p. 703
[21] S.M. Seo, H.W. Jeong, Y.K. Ahn, D.W. Yun, J.H. Lee, Y.S. Yoo, Mater. Charact. 89, 43 (2014)

[22] S.M. Seo, in Superalloys, ed. by R.C. Reed, K.A. Green, P. Caron, T.P. Gabb, M.G. Fahrmann, E.S. Huron, S.R. Woodard (TMS, Philadelphia, 2008), p. 277

[23] M. Pröbstle, S. Neumeier, P. Feldner, R. Rettig, H. Helmer, R. Singer, M. Göken, Mater. Sci. Eng. A 676, 411 (2016)

[24] L. Liu, G. Zu, T. Jin, Adv. Mater. Res. 634-638, 1724 (2013)

[25] C.M.F. Rae, R.C. Reed, Acta Mater. 49, 4113 (2001)

[26] J. Wu, Y.C. Liu, C. Li, Y.T. Wu, X.C. Xia, H.J. Li, Acta Metall. Sin. 56, 21 (2020). (in Chinese)

[27] S.G. Tian, M.G. Wang, L. Tang, B.J. Qian, J. Xie, Mater. Sci. Eng. A 527, 5444 (2010)

[28] X.Z. Qin, J.T. Guo, C. Yuan, G.X. Yang, L.Z. Zhou, H.Q. Ye, J. Mater. Sci. 44, 4840 (2009)

[29] A.S. Wilson, M.C. Hardy, H.J. Stone, J. Alloys Compd. 789, 1046 (2019) 